\title{
Childhood motor impairment is associated with male anxiety at 11 and 16 years
}

Sigurdsson E, van Os J, Fombonne E. Are impaired childhood motor skills a risk factor for adolescent anxiety? Results from the 1958 U.K Birth Cohort and the National Child Development Study. American Journal of Psychiatry 2002 June; 159: $1044-6$.

\section{QUESTION: Do delayed childhood motor skills predict persistent anxiety in adolescence?}

Design

Longitudinal cohort study.

\section{Setting}

United Kingdom.

\section{Participants}

6850 people born during one week in March 1958 Data were collected when participants were 7,11 and 16 years old.

Sources of funding: None specified

For correspondence: Dr Sigurdsson,

Department of

Psychiatry,

Landspitali-University

Hospital, Reykjavik,

Iceland.

engilbs@landspitali.is

\section{Assessment of risk factors}

Motor impairment was measured using parental reports of the child's not walking at 18 months of age and teacher reports of poor hand control at age 7; 'clumsiness' at age 7; poor hand control at 11 years, and participating in an ongoing national birth cohort study.

poor coordination at 11 years. Demographic information and emotional problems were controlled for.

\section{Main outcome measures}

Maternally rated anxiety at 11 and 16 years.

\section{Main results}

$8 \%$ of boys and $3 \%$ of girls had motor impairment. Boys with poor motor skills at age 7 had higher levels of anxiety at age 11 and 16 (odds ratio 3.29, 95\% CI 2 to 5.4). There was no relationship between childhood motor skills and anxiety in teenage girls (odds ratio $0.95,95 \%$ CI 0.3 to 2.7$)$.

\section{Conclusions} anxiety in 11 and 16 year old males, but not females.
Childhood motor development is associated with

\section{COMMENTARY}

Although learning disabilities and attention deficit disorder have been linked to poor mental health outcomes, the relationship between childhood motor coordination and social and emotional problems in adolescence has received less research attention. This is the first large scale longitudinal study to reinforce the findings of Shaffer ${ }^{1}$ and Hellgren $e t$ al..$^{2}$ In previous studies motor impaired children had concomitant learning or attentional problems that may have contributed to the result. This study is open to the same potential criticism, but the sample size and selection method lend strength to the finding that impaired motor skills in childhood are a risk factor for persistent anxiety in adolescence.

Although the authors do not use the term, the criteria used to select children are consistent with the definition of 'developmental coordination disorder' (DCD) outlined in DSM-IV-TR. ${ }^{3}$ Many physicians believe that mild childhood motor impairment is of no concern, viewing it either as normal variation or as a maturational delay. ${ }^{4}$ Recent research, including this study, suggests that these beliefs are no longer tenable. ${ }^{5}$ Children with coordination difficulties have trouble with basic tasks that they need to do every day - dressing, printing, tying shoes, catching and throwing balls. A child who is unable to perform these activities may experience significant social and academic problems during the school years; it is hardly surprising that behavioural and emotional problems often ensue. As the authors propose, before assuming that motor impairment causes persistent anxiety, we must account for the differential effect found in boys and girls. During early and middle childhood, most of the social interactions and leisure activities in which boys participate are closely linked to sports and physical activity. Boys who have coordination difficulties may be disadvantaged in the playground, bullied and may become passive and withdrawn. The same pattern may not hold for girls who can engage in verbally-oriented and imaginative social and play activities. Like most other neurodevelopmental disorders, DCD is more common in boys than girls, contributing further to the gender bias.

This study, while not definitive, raises interesting clinical and research issues. Are the mental health problems of children with DCD secondary manifestations of the disorder or do they arise because children are unable to participate successfully in the typical activities of childhood? Practitioners need to recognise the extent to which mild motor difficulties may impact on children's ability to perform daily self-care, social, academic and leisure tasks. Timely intervention will be seen not just as skill remediation but as preventing the development of subsequent problems. Further longitudinal research is required to disentangle the issue of primary versus secondary impairments in children with coordination difficulties.

Cheryl Missiuna, $\mathrm{PhD}$ OTReg (Ont) Assistant Professor School of Rehabilitation Science and CanChild McMaster University, Canada

1 Shaffer D, Schonfield I, O'Connor PA et al. Neurological soft signs and their relationship to psychiatric disorder and intelligence in childhood and adolescence. Archives of General Psychiatry 1985; 42,343-51.

2 Hellgren L, Gillberg IC, Bagenholm A et al. Children with deficits in attention, motor control and perception (DAMP) almost grown up: Psychiatric and personality disorders at age 16 years. Journal of Child Psychology and Psychiatry 1994; 35, 1255-71.

3 American Psychiatric Association. Diagnostic and statistical manual of mental disorders. Fourth edition. Washingtom, DC: American Psychiatric Association, 2000. Polatajko HJ. Developmental coordination disorder (DCD): Alias the clumsy child syndrome. In Whitmore K, Hart H, Willems G (eds). A Neurodevelopmental Approach to Specific Learning Disorders. London: MacKeith Press, 1999: 119-33.

5 Cantell M, Kooistra L. Long-term outcomes of developmental coordination disorder. In Cermak SA, Larkin D (eds). Developmental Coordination Disorder. Albany, NY: Delmar. 2002: 23-38. 